\title{
Rapid, reliable diagnosis of chlamydial ophthalmia by means of monoclonal antibodies
}

\author{
DAVID A HAWKINS, ${ }^{22}$ ROGER S WILSON, ${ }^{3}$ BRENDA J THOMAS, ${ }^{1}$ AND \\ ROGER T EVANS'
}

From the 'Division of Sexually Transmitted Diseases, MRC Clinical Research Centre, Harrow, Middlesex, the ${ }^{2}$ Praed Street Clinic, St Mary's Hospital, Praed Street, Paddington, London W2, and the ${ }^{3}$ Western Ophthalmic Hospital, Marylebone Road, London W2

SUMMARY The use of fluorescein-conjugated monoclonal antibody (Syva, UK) provided a rapid reliable diagnostic test for Chlamydia trachomatis in conjunctival samples from 100 adults with acute follicular conjunctivitis and seven babies with suspected chlamydial ophthalmia neonatorum. Elementary bodies (EBs) were seen in smears from 11 of the adults, and culture confirmed $C$. trachomatis infection in nine of them. Both tests were positive with specimens from four of the neonates. No specimens from either group of patients produced a negative result in the smear test but a positive result by culture. However, the two adult patients with chlamydial ophthalmia who had negative cultures but were EB-positive had both had prior topical tetracycline therapy.

Acute follicular conjunctivitis is a common problem in general practice and eye casualty departments. Many cases will be due to adenovirus infection and may resolve with symptomatic therapy. An important minority of cases, however, will be due to infection with oculogenital strains of Chlamydia trachomatis, when there may be concurrent (often asymptomatic) genital infection for which there is specific therapy.

Definitive diagnosis of conjunctival infection with C. trachomatis may be made by detecting inclusions in conjunctival cell scrapings or by isolating the organism in cell culture. ${ }^{1-3}$ The latter method is more sensitive, but as chlamydiae are labile care must be taken with storage and transport of specimens to the laboratory. In addition isolation of chlamydiae in cell culture requires experience and constant control of sensitivity. Specimens are inoculated into McCoy cell cultures, and after 48 or 72 hours chlamydial inclusions are stained with Giemsa (or iodine) reagent.

Direct demonstration of inclusions in conjunctival scrapings stained with Giemsa provides a result within an hour of the specimen arriving at the laboratory, but it is a less sensitive method than culture. In proved chlamydial eye infections Giemsa staining of conjunctival smears detected up to only

Correspondence to Dr D A Hawkins, Clinical Research Centre, Division of Sexually Transmitted Diseases, Watford Road, Harrow, Middlesex HA1 3UJ.
$60 \%$ of cases, and fluorescent polyclonal antibody staining detected $80 \% .{ }^{34}$ However, very few inclusions are found even by the fluorescent antibody technique, so that often a prolonged search for the agent is necessary.

The ability to detect reliably extracellular elementary bodies (EBs) directly in conjunctival smears would obviate both the need for culture and its associated problems, and the laborious search for inclusions in conjunctival scrapings. Recently a fluorescein-labelled monoclonal antibody specific to C. trachomatis has become available and allows the more numerous EBs to be detected rapidly. This technique has been shown to be sensitive and specific, when compared with isolation, in detecting chlamydiae in specimens from the genital tract (urethra, cervix)..$^{56}$ The monoclonal antibody recognises specifically the major outer membrane protein (MOMP) of all 15 serovars (immunotypes) of $C$. trachomatis - that is $\mathrm{A}$, $B$, and $C$, causing trachoma, the oculogenital strains (D-K), and L1-L3 causing lymphogranuloma venereum - but it does not cross-react with C. psittaci. ${ }^{7}$

\section{Patients and methods}

\section{PATIENTS}

One hundred adult patients with acute follicular conjunctivitis and seven babies with ophthalmia neonatorum were studied. Younger adult patients 
under the age of 35 years were selected preferentially, though some older patients were included. All patients were asked about genitourinary symptoms and all had slit lamp examination. If possible swabs were taken from both conjunctivae whether or not they were considered to be diseased. Rapid detection of $C$. trachomatis EBs was not performed, but casualty officers were informed within a few days of patients with positive direct smear results. These patients were requested to see one of us (DAH) at the Praed Street Clinic for full investigations, including genital tests. Sexual contacts were requested to attend. Blood was also taken for chlamydial serology (microimmunofluorescence test). ${ }^{8}$ Patients were then treated with systemic tetracycline or erythromycin.

The seven babies were seen at Northwick Park Hospital and had a diagnosis of suspected chlamydial ophthalmia. The majority had had prior topical therapy (usually chloramphenicol) for their sticky eyes. The mothers (and their sexual partners) of the chlamydia-positive babies were referred for genital tests and subsequent therapy.

MONOCLONAL ANTIBODIES

These were obtained from Syva UK (Maidenhead, Berks). Conjunctival smears were examined by the Microtrak Chlamydia trachomatis direct fluorescent antibody reagent. Control preparations were obtained from Syva UK.

\section{PREPARATION OF SMEARS}

Eye swabs were obtained by everting the lower lid and firmly drawing an ENT swab (MW 142; Medical Wire and Equipment Co., Corsham, Wilts) along the tarsal conjunctiva. Genital material was obtained as described previously. ${ }^{5}$

A smear was made by rubbing the swab immediately it had been taken firmly and evenly over a circumscribed uncoated area $(13 \mathrm{~mm}$ diameter) of a microscope slide coated with polytetrafluoroethylene, so that some material was visible on the slide. The smear was allowed to dry and then fixed immediately by covering the area with methanol (or acetone); this was allowed to evaporate without the slide being moved. Fixed smears were then stored in covered slide boxes at $4^{\circ} \mathrm{C}$ until transfer to the laboratory.

\section{CHLAMYDIAL ISOLATION}

After a smear had been made, the same swab was immediately agitated vigorously and expressed in 1.0 $\mathrm{ml}$ of sucrose-phosphate (2SP) medium with antibiotics. This was snap frozen and stored in liquid nitrogen. Chlamydiae were isolated subsequently in cycloheximide-treated McCoy cells as described previously. ${ }^{9}$
STAINING AND EXAMINATION OF SMEARS

Before being stained with monoclonal antibody fixed smears that had been refrigerated were allowed to reach room temperature. $30 \mu \mathrm{l}$ of the Microtrak direct monoclonal antibody were spread over the smear and the slide was incubated at $37^{\circ} \mathrm{C}$ for $15 \mathrm{~min}$ in a moist chamber. Excess reagent was then removed by immersing the slide in distilled water, followed by a $5 \mathrm{~min}$ wash with stirring. After being dried the smear was mounted under a coverslip with Microtrak chlamydia direct specimen mounting fluid and examined with a Nikon L-ke microscope fitted with an epifluorescence attachment.

All the smears were coded and then read by one observer (BJT), who also examined coded Giemsastained McCoy cell monolayers at a later date. All

Table 1 Demonstration of chlamydiae by direct test and culture in adult patients with conjunctivitis at presentation

\begin{tabular}{|c|c|c|c|c|c|}
\hline \multirow[t]{3}{*}{ Study no. } & \multirow[t]{3}{*}{ Sex } & \multirow[t]{3}{*}{ Eye } & \multicolumn{3}{|c|}{ C. trachomatis detection } \\
\hline & & & \multirow{2}{*}{$\begin{array}{l}\text { Direct } \\
\boldsymbol{I F}\end{array}$} & \multicolumn{2}{|l|}{ Culture } \\
\hline & & & & $\begin{array}{l}\text { Giemsa } \\
\text { stain }\end{array}$ & $\begin{array}{l}\text { Monoclonal } \\
\text { antibody }(C C)\end{array}$ \\
\hline 7 & $\mathbf{M}$ & $\begin{array}{l}\mathbf{L} \\
\mathbf{R}\end{array}$ & $\begin{array}{l}+++ \\
\mathrm{NT}\end{array}$ & $\begin{array}{l}+++ \\
\mathbf{N T}\end{array}$ & $\begin{array}{l}+t+t \\
\mathbf{N T}\end{array}$ \\
\hline 41 & $\mathbf{M}$ & $\begin{array}{l}\mathbf{L} \\
\mathbf{R}\end{array}$ & $\begin{array}{l}+++ \\
-\end{array}$ & $\begin{array}{l}+++ \\
-\end{array}$ & $\begin{array}{l}+t+ \\
-\end{array}$ \\
\hline 44 & $\mathbf{F}$ & $\begin{array}{l}\mathbf{L} \\
\mathbf{R}\end{array}$ & $\begin{array}{l} \pm \\
-\end{array}$ & $\begin{array}{l}- \\
-\end{array}$ & $\begin{array}{l}- \\
-\end{array}$ \\
\hline 46 & $\mathbf{F}$ & $\begin{array}{l}\mathbf{L} \\
\mathbf{R}\end{array}$ & $\begin{array}{l}+t+ \\
+\end{array}$ & $\begin{array}{l}+t \\
\pm\end{array}$ & + \\
\hline 49 & $\mathbf{F}$ & $\begin{array}{l}\mathbf{L} \\
\mathbf{R}\end{array}$ & $\bar{t}$ & - & - \\
\hline 61 & $\mathbf{M}$ & $\begin{array}{l}\mathbf{L} \\
\mathbf{R}\end{array}$ & $\begin{array}{l}+ \\
-\end{array}$ & $\begin{array}{l}++ \\
-\end{array}$ & $\begin{array}{l}++ \\
-\end{array}$ \\
\hline 67 & $\mathbf{M}$ & $\begin{array}{l}\mathbf{L} \\
\mathbf{R}\end{array}$ & $\begin{array}{l}+t+ \\
+t\end{array}$ & $\begin{array}{l}+++t \\
+t\end{array}$ & $\begin{array}{l}++t \\
+t\end{array}$ \\
\hline 78 & $\mathbf{F}$ & $\begin{array}{l}\mathbf{L} \\
\mathbf{R}\end{array}$ & $\begin{array}{l}\text { NT } \\
+\end{array}$ & $\begin{array}{l}\mathbf{N T} \\
+\end{array}$ & $\begin{array}{l}\mathbf{N T} \\
-\end{array}$ \\
\hline 80 & $\mathbf{M}$ & $\begin{array}{l}\mathbf{L} \\
\mathbf{R}\end{array}$ & $\begin{array}{l}\text { NT } \\
+\end{array}$ & $\begin{array}{l}\mathbf{N T} \\
+\end{array}$ & $\begin{array}{l}\mathbf{N T} \\
+\end{array}$ \\
\hline 83 & $\mathbf{M}$ & $\begin{array}{l}\mathbf{L} \\
\mathbf{R}\end{array}$ & $\begin{array}{l}+++ \\
\mathbf{N T}\end{array}$ & $\stackrel{+}{\mathbf{N T}}$ & $\begin{array}{l}++ \\
\mathbf{N T}\end{array}$ \\
\hline 104 & $\mathbf{M}$ & $\begin{array}{l}\mathbf{L} \\
\mathbf{R}\end{array}$ & $\begin{array}{l}++ \\
-\end{array}$ & $\begin{array}{l}+ \\
-\end{array}$ & $\begin{array}{l}+t \\
-\end{array}$ \\
\hline
\end{tabular}

All other patients had negative IF/Giemsa/CC at initial visit and were not further tested.

IF $=$ Immunofluorescence. $\mathbf{C C}=$ Culture confirmation. $\mathbf{N T}=\mathbf{N o t}$ tested.

$\pm=1-10$.

$+=11-100$.

$++=101-1000$.

$+++=1001-10000$.

$++++=>10000$

The above ranges ( \pm to ++++$)$ apply to elementary bodies seen in the direct test or inclusions seen in cell monolayers when the culture technique is used. 
Table 2 Patient 67: male, aged 33

\begin{tabular}{|c|c|c|c|c|c|c|c|c|}
\hline \multirow[t]{2}{*}{ Date } & \multicolumn{2}{|l|}{ LEye } & \multicolumn{2}{|c|}{$R$ Eye } & \multicolumn{3}{|c|}{ Urethra } & \multirow[t]{2}{*}{ Therapy } \\
\hline & $I F$ & Cult & $I F$ & Cult & $I F$ & Cult & $P M N L$ & \\
\hline 1 Dec 1983 & & & & & & & & $\begin{array}{l}\text { Topical } \\
\text { chloramphenicol } \\
1 / 52\end{array}$ \\
\hline 8 Dec 1983 & +++ & ++++ & ++ & ++ & NT & NT & NT & $\begin{array}{l}\text { Topical } \\
\text { tetracycline }\end{array}$ \\
\hline 9 Dec 1983 & ++ & + & + & - & ++ & +++ & 40 & $\begin{array}{l}\text { Systemic } \\
\text { doxycycline }\end{array}$ \\
\hline 16 Dec 1983 & - & - & - & - & - & - & 15 & \\
\hline 23 Dec 1983 & - & - & - & - & - & - & 0 & \\
\hline
\end{tabular}

Casual sexual partners four to six weeks previously in Phillipines. Three weeks bilateral follicular conjunctivitis. Two weeks dysuria and urethral discharge. Topical chloramphenicol for one week to both eyes prior to initial testing. Wife examined and found to have chlamydial mucopurulent cervicitis.

PMNL=polymorphonuclear leucocytes. For symbols see Table 1.

specimens for attempted isolation of chlamydiae were processed by one person (RTE), who also examined coded McCoy cell monolayers by a culture confirmation (CC) technique using fluoresceinlabelled monoclonal antibody (Syva) to detect inclusions rather than by Giemsa staining.

\section{Results}

DETECTION OF CHLAMYDIAE DIRECTLY IN SMEARS OR BY CULTURE (GIEMSA STAINING OR CC)

\section{Adults}

EBs were detected in the conjunctival smears of eleven $(11 \%)$ of the adult patients. Nine of these were subsequently confirmed by culture (Table 1 ). Both of the two culture-negative patients had had prior topical tetracycline therapy (see below). The remaining 89 patients whose specimens were negative in the direct smear monoclonal antibody test were also culture negative.

Seven of the 11 patients who had positive direct tests had both eyes swabbed; bilateral infection with chlamydiae was found in two of these. No clinically unaffected eyes were positive. Seventy of the 100 adult patients had both eyes swabbed, making a total of 170 specimens. Taking culture as reference, this gives a specificity of $99 \%$ and a sensitivity of $100 \%$.

Genital tests. Five of the 11 patients whose eye swabs were positive by the direct smear test defaulted after their first visit; one of these had received systemic tetracycline. The other six were contacted and agreed to be seen at the Praed Street Clinic for further assessment. While waiting for this appointment all had topical tetracycline therapy for their eye infections. The results of eye and genital tests from two of these patients are shown in Tables 2 and 3.

\section{Effect of therapy on direct test and culture}

Topical treatment. Topical tetracyclines appear to have a greater effect on culture than on the direct test. Thus a smear from the right eye of patient 49 contained 10-100 EBs while the culture was negative. This patient had been using tetracycline and Albucid (sulphacetamide) eye drops for 10 days prior to her presentation. Consequently the EBs seen may not have been viable. Unfortunately the patient defaulted, so that the follow-up genital tests were not possible. The other culture-negative patient (no. 44) had fewer than $10 \mathrm{EBs}$ in a conjunctival smear from her left eye and had also received prior topical tetracycline therapy (tetracycline ointment for two weeks). Patient 67 had both eyes positive by both tests from

Table 3 Patient 46: female, aged 24

\begin{tabular}{|c|c|c|c|c|c|c|}
\hline \multirow[t]{2}{*}{ Date } & \multicolumn{2}{|c|}{ L Eye } & \multicolumn{2}{|c|}{$R$ Eye } & Cervix* & \multirow[t]{2}{*}{ Therapy } \\
\hline & $I F$ & Cult & IF & Cult & IF Cult & \\
\hline 3 Nov 1983 & & & & & & $\begin{array}{l}\text { Topical } \\
\text { chlor- } \\
\text { amphenicol }\end{array}$ \\
\hline 17 Nov 1983 & +++ & ++ & + & \pm & NT NT & $\begin{array}{l}\text { Topical } \\
\text { tetracycline }\end{array}$ \\
\hline 24 Nov 1983 & ++ & ++ & \pm & + & + \pm & $\begin{array}{l}\text { Systemic } \\
\text { doxycycline }\end{array}$ \\
\hline 25 Nov 1983 & ++ & + & \pm & \pm & NT NT & \\
\hline 30 Nov 1983 & + & - & - & - & NT NT & \\
\hline 6 Nov 1983 & - & - & - & - & $-\quad-$ & \\
\hline
\end{tabular}

Casual partner two months previously in Turkey. Conjunctivitis for one month prior to presentation. No genital symptoms. Topical chloramphenicol for latter two weeks. Progressive clinical improvement with systemic doxycycline.

${ }^{*}$ Rectal and throat tests also positive. 
samples taken at presentation. One day later, however, after topical tetracycline therapy chlamydiae were not isolated by culturing specimens from the right eye, although $>100$ EBs were shown by direct immunofluorescence (Table 2).

Systemic treatment. Attempts to visualise EBs directly and to culture chlamydiae in cell culture from genital and eye sites were unsuccessful after one week or more of systemic tetracycline therapy. In one patient (no. 46), however, 10-100 EBs were seen after six days in a specimen from what had been a severely affected left eye, but the result of culture was negative (Table 3 ). Presumably these were dead EBs.

\section{NEONATES}

EBs were detected in the conjunctival smears of 4 $(57 \%)$ of seven babies with suspected chlamydial conjunctivitis. C. trachomatis was cultured in every case and, conversely, the micro-organism could not be cultured in the three smear-negative babies. One of these positive smears had fewer than $10 \mathrm{EBs}$, whereas the other three had more than 100.

\section{MICROIMMUNOFLUORESCENCE SEROLOGY}

This was performed only on patients who had genital tests. All except patient number 44 were positive with IgG titres (against pooled D-K, lymphogranuloma venereum antigens) ranging from 1:16-1:128.

\section{Discussion}

The results of the study show that conjunctivitis caused by oculogenital strains of $C$. trachomatis can be diagnosed rapidly and easily by staining conjunctival smears with a fluorescent monoclonal antibody.

The conjunctival swabs were taken by a number of different medical and nursing staff in a busy eye casualty department. Nevertheless, samples from clinically affected eyes usually contained sufficient epithelial cells to indicate that they were adequate for testing. On the few occasions when inadequate smears were provided they were readily identified, and additional specimens were requested if this was clinically indicated. Eye specimens produced few non-specifically staining artefacts compared with genital specimens and so were easy to interpret. We considered as artefacts any fluorescing particles which did not have the characteristic EB morphology, colour, and brightness. ${ }^{510}$ Subsequent to this study we have looked at a number of conjunctival smears taken soon after patients had applied ointment based preparations. These smears were covered with numerous fluorescent globules, which could not be confused with EBs, but made the search for small numbers of them more difficult.
The fluorescent monoclonal antibody test for EBs was at least as sensitive as routine cell culture for detecting chlamydial eye disease. It was also highly specific, though patient 44 had negative genital tests and microimmunofluorescence serology, so that the result in her case may have been a false positive. 112 All the eye samples found to be negative by the monoclonal antibody test were confirmed as negative by culture. The high specificity and sensitivity of the test support our claim that the technique is reliable. This does not surprise us considering previous reports of success with samples from the genital tract. ${ }^{56}$

Although the prevalence of chlamydial ophthalmia in the United Kingdom is unknown, in a large study over five years (1976-80) $18 \%$ of new patients attending the Keratoconjunctivitis Clinic at Moorfields Eye Hospital were diagnosed as having adult chlamydial ophthalmia. ' However, in a recent study from the same hospital of 142 consecutive patients with acute conjunctivitis only $7(5 \%)$ of the patients had chlamydial infection confirmed by culture, though serological evidence suggestive of infection was found in another $5(4 \%)$ of the patients. ${ }^{13}$ Ours was not a prevalence study, but the positivity rate, despite some selection, was only $11 \%$. It is probable that this rate was reduced by an adenovirus epidemic at the time of the study. As noted by others, patients with chlamydial ophthalmia could not be readily identified by history and examination. Positive patients were not necessarily particularly promiscuous, and many had asymptomatic genital infections.

The use of the monoclonal antibody technique to diagnose chlamydial eye disease has obvious advantages. First, the problems of storage and transport of specimens associated with an isolation service in a distant laboratory are eliminated. Second, selected patients, for example neonates with conjunctivitis, 'can be offered a very rapid service, with results available within 30 minutes of the specimen reaching the laboratory. Third, the test is relatively painless compared with conjunctival scrapings (the other method with which rapid results can be obtained). Finally, the combination of a quick and reliable technique will allow the early identification of those patients who require systemic therapy for both eye disease and genital tract infection.

We thank the medical and nursing staff of the Western Ophthalmic Hospital for their invaluable help with this study and Dr D TaylorRobinson for his encouragement and critical appraisal of the manuscript.

\section{References}

1 Viswalingam ND, Wishart MS, Woodland RM. Adult chlamydial ophthalmia (paratrachoma). Br Med Bull 1983; 39: 123-7. 
2 Darougar S, Woodland RM, Jones BR, et al. Comparative sensitivity of fluorescent antibody staining of conjunctival scrapings and irradiated McCoy cell culture for the diagnosis of hyperendemic trachoma. Br J Ophthalmol 1980; 64: 276-8.

3 Schachter J, Dawson CR. Human chlamydial infections. Littleton, Mass: PSG Publishing Co., 1978: 108.

4 Schachter J, Dawson CR, Balas S, Jones P. Evaluation of laboratory methods for detecting acute TRIC agent infection. Am J Ophthalmol 1970; 70: 375-80.

5 Thomas BJ, Evans RT, Hawkins DA, Taylor-Robinson D. The sensitivity of detecting Chlamydia trachomatis elementary bodies in smears by use of a fluorescein-labelled monoclonal antibody compared to that of conventional chlamydial isolation. $J$ Clin Pathol 1984; 37: 812-6.

6 Tam MR, Stamm WE, Handsfeld HH, et al. Culture-independent diagnosis of Chlamydia trachomatis using monoclonal antibodies. N Engl J Med 1984; 310: 1146-50.

7 Stephens RS, Tam MR, Kuo CC, Nowinski RC. Monoclonal antibodies to Chlamydia trachomatis: antibody specificities and antigen characterization. J Immunol 1982; 128: 1083-9.

8 Wang SP, Grayston JT. Human serology in Chlamydia tracho- matis infection with microimmunofluorescence. $J$ Infect Dis 1974; 130: 388-97.

9 Thomas BJ, Evans RT, Hutchinson GR, Taylor-Robinson D. Early detection of chlamydial inclusions combining the use of cycloheximide-treated McCoy cells and immunofluorescence staining. J Clin Microbiol 1977; 6: 285-92.

10 Hawkins DA, Thomas BJ, Taylor-Robinson D. Rapid detection of Chlamydia trachomatis with monoclonal antibodies. Lancet 1984; ii: 38.

11 Darougar S, Treharne JD, Minassian D, et al. Rapid serological test for diagnosis of chlamydial ocular infections. BrJ Ophthalmol 1978; 62: 503-8.

12 Treharne JD, Dines RJ, Darougar S. Serological responses to chlamydial ocular and genital infections in the United Kingdom and Middle East. In: Hobson D, Holmes KK, eds. Nongonococcal urethritis and related infections. Washington, DC: American Society for Microbiology, 1977: 249-58.

13 Wishart PK, James C, Wishart MS, Darougar S. Prevalence of acute conjunctivitis caused by chlamydia, adenovirus, and herpes simplex virus in an ophthalmic casualty department. $\mathrm{Br} J$ Ophthalmol 1984; 68: 653-5. 